\title{
Solanum Whitefly, Pepper Whitefly (Suggested Common Names) Aleurotrachelus trachoides Back (Insecta: Hemiptera: Aleyrodidae: Aleyrodinae) ${ }^{1}$
}

\author{
Vivek Kumar, Antonio Francis, Muhammad Ahmed, Catharine Mannion, lan Stocks, Eric \\ Rohrig, Cindy McKenzie, and Lance Osborne²
}

\section{Introduction}

Native to the Neotropical region, Aleurotrachelus trachoides Back, commonly known as the solanum or pepper whitefly, is an emerging pest of pepper and many other horticultural crops in the United States. It has been in the United States for more than five decades as an intermittent pest of pepper although, until recently, was never considered a key pest of economic importance. However, in the past few years, records of its spread and damage have been reported from private residences and nurseries throughout Florida. Feeding by this pest can cause stress to the plant by removing nutrients and water. Additionally, the feeding exudates excreted as honeydew also promote the growth of black sooty mold.

\section{Synonymy}

After Evans (2007)

Aleyrodes trachoides Back, 1912

Aleurotrachelus trachoides (Back) Quaintance \& Baker, 1914
Aleurotulus bodkini Baker \& Moles, 1923

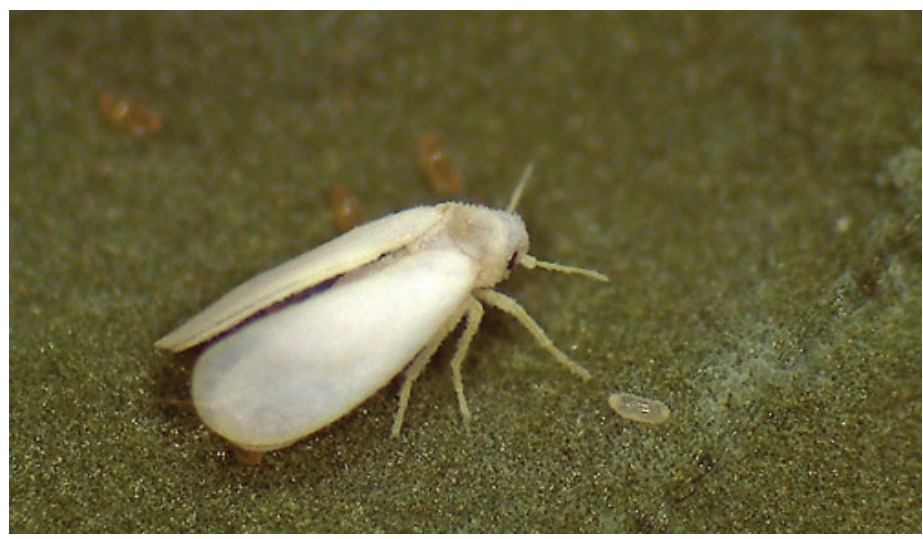

Figure 1. Aleurotrachelus trachoides Back feeding on Capsicum annuum L. (pepper) leaf.

Credits: Vivek Kumar, UF/IFAS

\section{Distribution}

According to a recent report of the European and Mediterranean Plant Protection Organization (EPPO 2015), Aleurotrachelus trachoides has a wide distribution in Central and South America and the Caribbean, where it has been reported from Antigua and Barbuda, Bahamas, Barbados,

1. This document is EENY662, one of a series of the Department of Entomology and Nematology, UF/IFAS Extension. Original publication date July 2016. Visit the EDIS website at http://edis.ifas.ufl.edu. This document is also available on the Featured Creatures website at http://entnemdept.ifas.ufl.edu/ creatures/.

2. Vivek Kumar, post doctoral associate, Department of Entomology and Nematology, UF/IFAS Mid-Florida Research and Education Center; Antonio Francis, Florida Department of Agriculture and Consumer Services, Division of Plant Industry; Muhammad Z. Ahmed, post doctoral associate, Department of Entomology and Nematology, UF/IFAS Tropical REC; Catharine Mannion, professor, Department of Entomology and Nematology, UF/ IFAS Tropical REC; lan Stocks, Florida Department of Agriculture and Consumer Services, Division of Plant Industry; Eric Rohrig, Florida Department of Agriculture and Consumer Services, Division of Plant Industry; Cindy L. McKenzie, United States Horticulture Research Laboratory, ARS-USDA; and Lance S. Osborne, professor, Department of Entomology and Nematology, UF/IFAS Mid-Florida REC; UF/IFAS Extension, Gainesville, FL 32611.

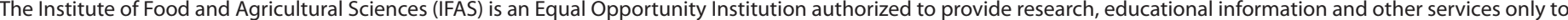

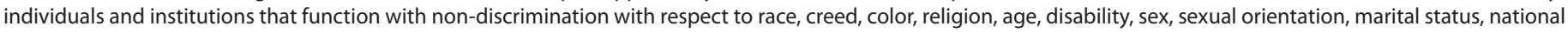
origin, political opinions or affiliations. For more information on obtaining other UF/IFAS Extension publications, contact your county's UF/IFAS Extension office. 
Belize, Cayman Islands, Costa Rica, Cuba, Curaçao, Dominica, Dominican Republic, El Salvador, Guadeloupe,

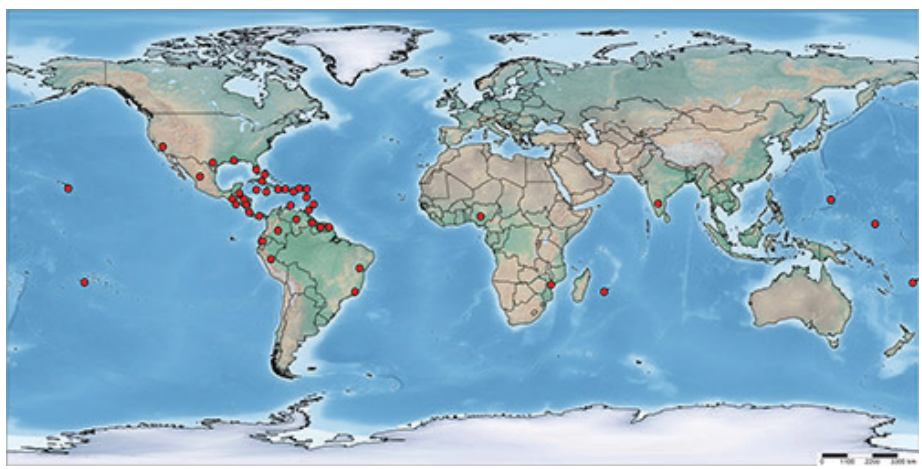

Figure 2. Global distribution map of Aleurotrachelus trachoides Back. Credits: Vivek Kumar, UF/IFAS

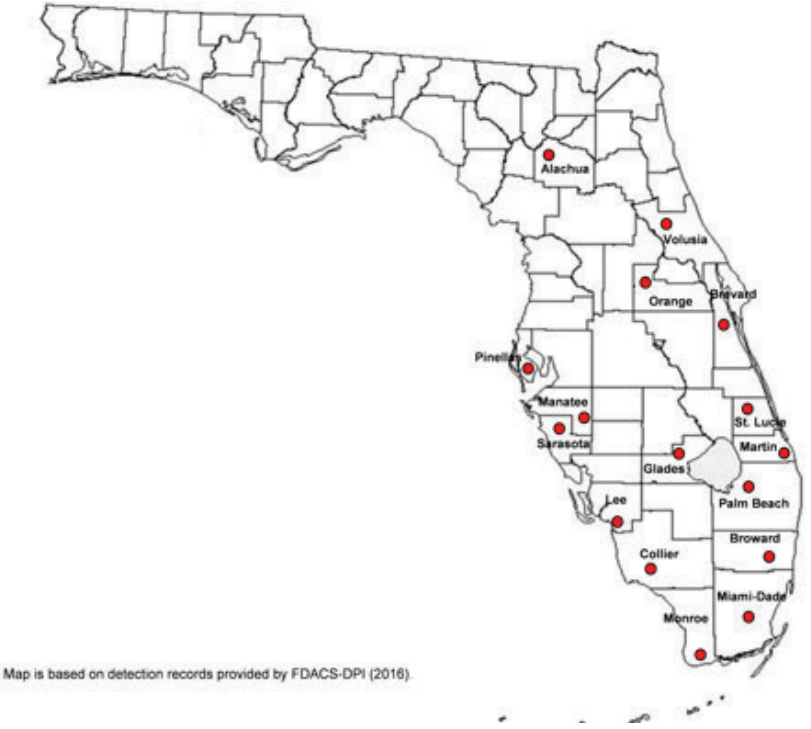

Figure 3. Distribution map of Aleurotrachelus trachoides Back, in Florida.

Credits: Vivek Kumar, UF/IFAS

Guatemala, Haiti, Honduras, Jamaica, Martinique, Nicaragua, Panama, Puerto Rico, Trinidad and Tobago, Virgin Islands, Brazil (Bahia, Rio do Janeiro), Colombia, Ecuador (Galapagos), Guiana, Guyana, Peru, Suriname, and Venezuela. In North America, its presence has been confirmed in Mexico and the US (California, Florida, Hawaii, Louisiana, and Texas). Outside the Americas, Aleurotrachelus trachoides has been recorded from Africa (Mozambique, Nigeria and Reunion) and Oceania (Fiji, French Polynesia, Guam and Micronesia). Except for a few interception records, established populations of Aleurotrachelus trachoides have not been reported from Europe. In Asia, it was recently recorded in Karnataka, India on Duranta spp. (Ramanujam et al. 2014).

According to Florida Department of Agriculture and Consumer Services-Division of Plant Industry (FDACS-DPI) records from 1985 to 2015, Aleurotrachelus trachoides has been reported in the following Florida counties: Alachua, Brevard, Broward, Collier, Glades, Lee, Martin, Manatee, Miami-Dade, Monroe, Orange, Palm Beach, Pinellas, Sarasota, St. Lucie, and Volusia, but $45 \%$ of the records are from Miami-Dade County.

\section{Description and Biology}

Like other whiteflies, Aleurotrachelus trachoides develops through six life stages-egg, four nymphal instars and adult. Adults are small, $1-2 \mathrm{~mm}$ in size, and covered with a white waxy layer. Females lay tiny, translucent, oblong eggs on the undersides of leaves, which turn yellow to grayish-brown as they mature. FDACS scientists have conducted biological studies that show the life cycle (egg to adult) is approximately 29 days at room temperature $\left(25 \pm 1^{\circ} \mathrm{C}, 65 \pm 5 \% \mathrm{RH}\right.$, 12:12 L:D); eggs take an average of eight days for emergence of first instar nymphs, seven days for first instar to develop into second instar, six days for completion of second instar, four days for third instar, and four days for the fourth instar to emerge into an adult (Francis et al. unpublished data).

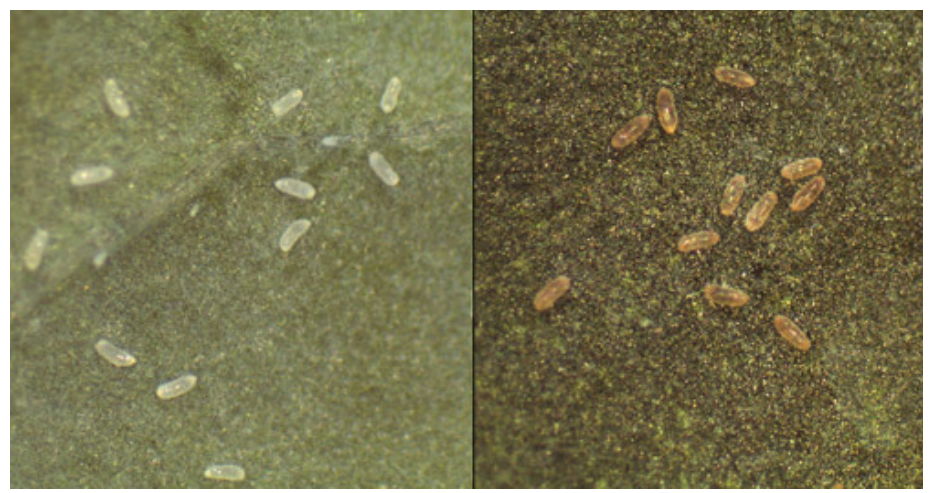

Figure 4. Eggs of Aleurotrachelus trachoides Back, on Capsicum annuum L. (pepper). Freshly laid eggs on left and old dark eggs on right. Credits: Vivek Kumar, UF/IFAS

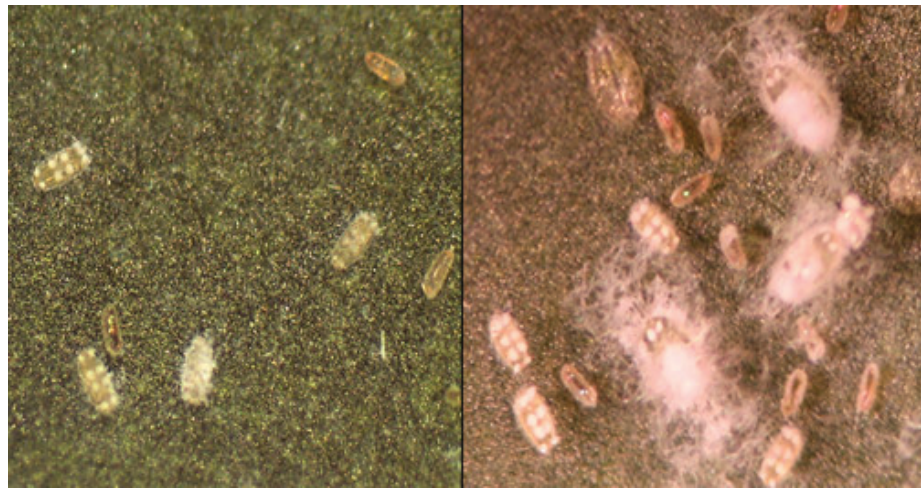

Figure 5. Initial stage of Aleurotrachelus trachoides Back with eight patches on the dorsal surface.

Credits: Vivek Kumar and Lance S. Osborne, UF/IFAS

Early nymphal instars are flat, round to oval shaped, light to golden yellow in color, and may also bear eight spherical patches on the dorsal surface. As the nymphal instars mature they become more convex, their color turns darker, 
and they produce a dense, cottony wax and long, thin, waxy filaments. The puparium of this species is used for taxonomic identification.

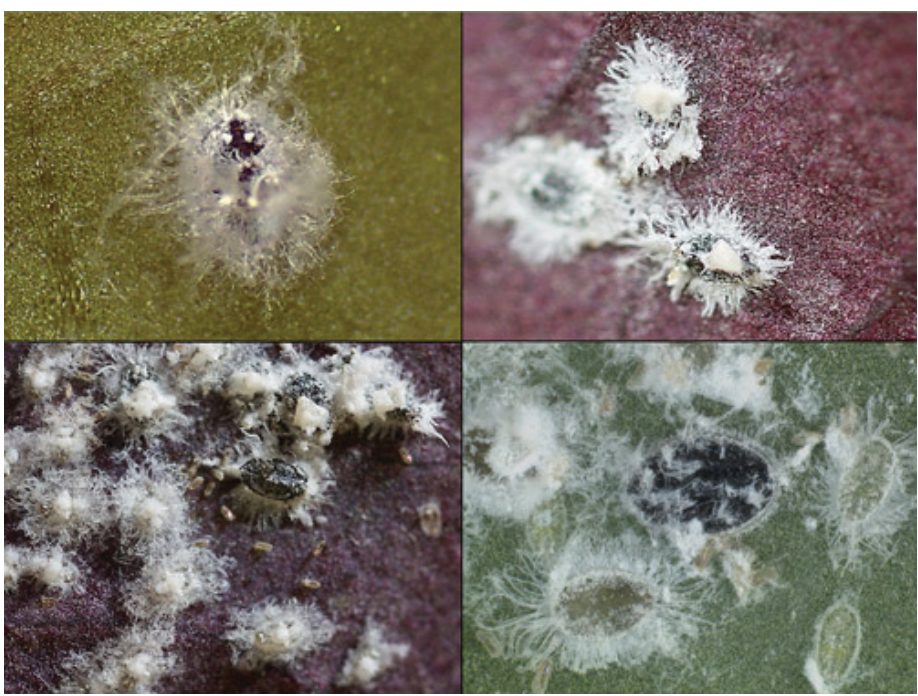

Figure 6. Immature stages of Aleurotrachelus trachoides Back, with wax and thin filaments.

Credits: Vivek Kumar and Lance S. Osborne, UF/IFAS; and lan Stocks, Florida Department of Agriculture and Consumer Services, Division of Plant Industry

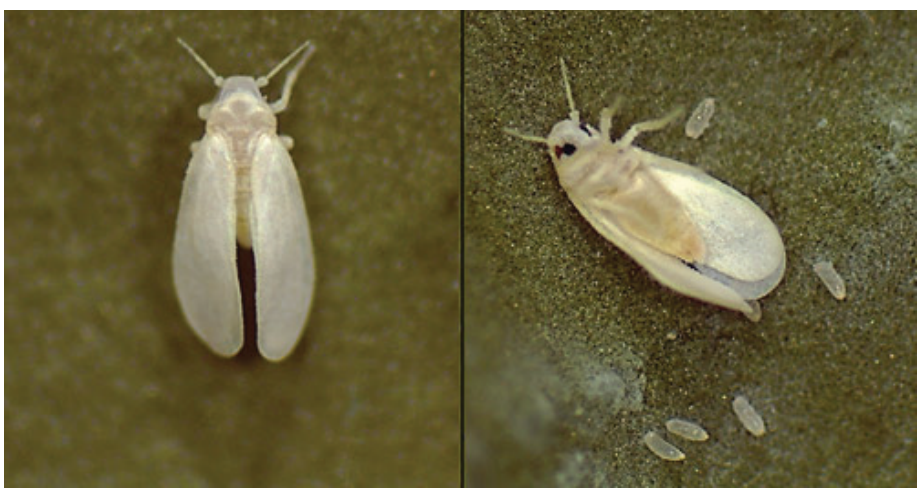

Figure 7. Adult of Aleurotrachelus trachoides Back, on Capsicum annuum L. (pepper).

Credits: Vivek Kumar, UF/IFAS

\section{Hosts}

Aleurotrachelus trachoides feeds on a wide range of hosts, including edible and ornamental plants, palms, and weeds. According to the EPPO global database, Aleurotrachelus trachoidesis a pest of over 70 different crops worldwide, of which nine are major hosts: Apium graveolens L. (celery), Capsicum annuum L. (sweet pepper), Capsicum frutescens L. (chili pepper), Ipomoea batatas (L.) Lam. (sweet potato), Nicotiana tabacum L. (tobacco), Persea americana Mill. (avocado), Rosa sp. (Rose), Solanum lycopersicum L. (tomato) and Solanum melongena L. (eggplant). However, all plant species reported may not be preferred hosts and may not require management. In the continental US, it was previously an infrequent pest in solanaceous crops; however, in the past few years it has been sampled regularly throughout the year from a growing list of potential hosts. It has been reported on more than 35 plant taxa in Florida, where most records were from pepper, sweet potato, pigeon berry, coconut palm, and tomato.

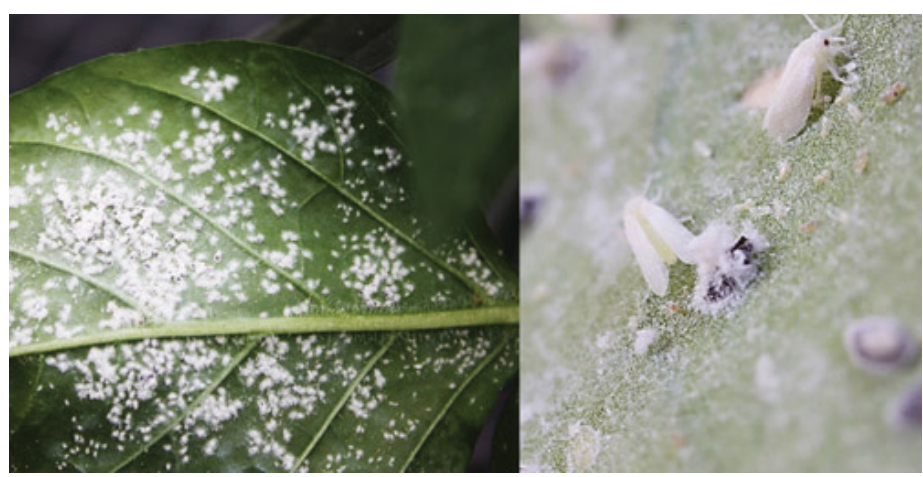

Figure 8. Capsicum annuum L. (pepper) leaf infested with Aleurotrachelus trachoides Back.

Credits: Lance S. Osborne and Vivek Kumar, UF/IFAS

\section{Damage}

Aleurotrachelus trachoides is a polyphagous pest, but prefers plants in the families Solanaceae and Convolvulaceae. It can damage the host by feeding with its needle-like mouthparts used to suck plant sap, resulting in stress to its host. Production of wax and honeydew, the latter an excellent substrate for the growth of a fungus called sooty mold, may also disrupt the photosynthetic process. In the case of a heavy infestation, it may lead to stunted growth of the host and reduced fruit production, ultimately affecting the aesthetic and/or economic value of the host plant(s). Aleurotrachelus trachoides is not a known vector of any plant damaging viruses (EPPO 2015).

\section{Symptoms of Damage}

- presence of white, waxy material

- presence of sticky honeydew around and below the whitefly infested area

- presence of black sooty mold

\section{Management}

Although adults can fly or be carried by wind and spread over small distances, the primary mode of dispersal is through movement of infested plant material, which includes cut flowers, whole plants, fruits, and vegetables (EPPO 2015). Thus, identification and effective monitoring are critical to reduce the movement and maintain populations below damaging levels. Being a fairly new pest of economic importance, not much information is available about effective management practices for Aleurotrachelus trachoides. However, as with other whiteflies, soaps and horticultural oils can be used to suppress early infestations, 
and effective control can be achieved using systemic application of certain insecticides.

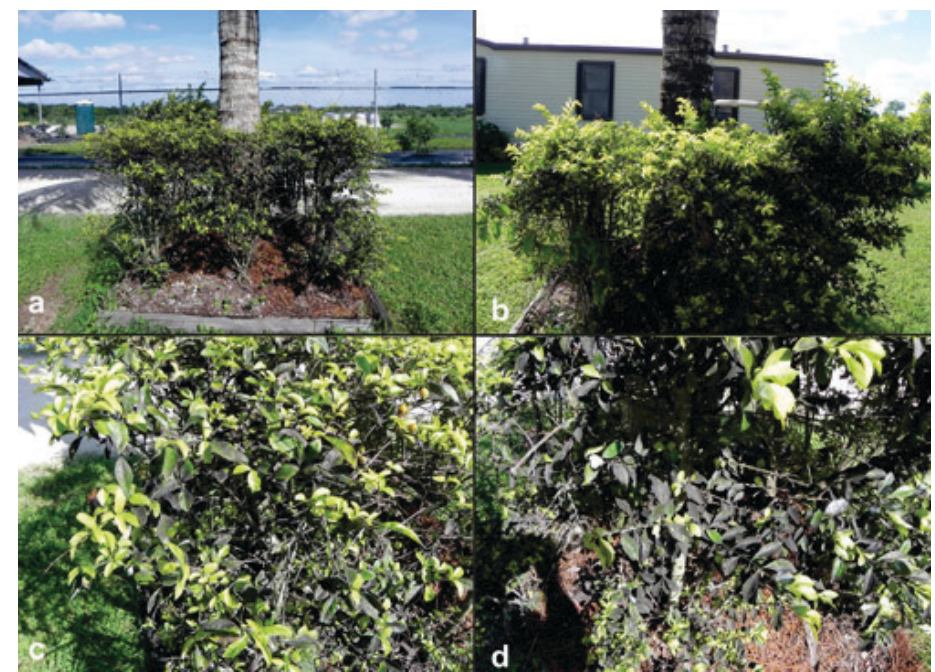

Figure 9. Plant infested with Aleurotrachelus trachoides Back. Infestation on Duranta erecta L. (pigeon berry); a and $\mathrm{c}$ is front side and $b, d$ is back side of the infested plant in Homestead. Notice the sooty mold on leaves.

Credits: Muhammad Z. Ahmed and Catharine Mannion, UF/IFAS

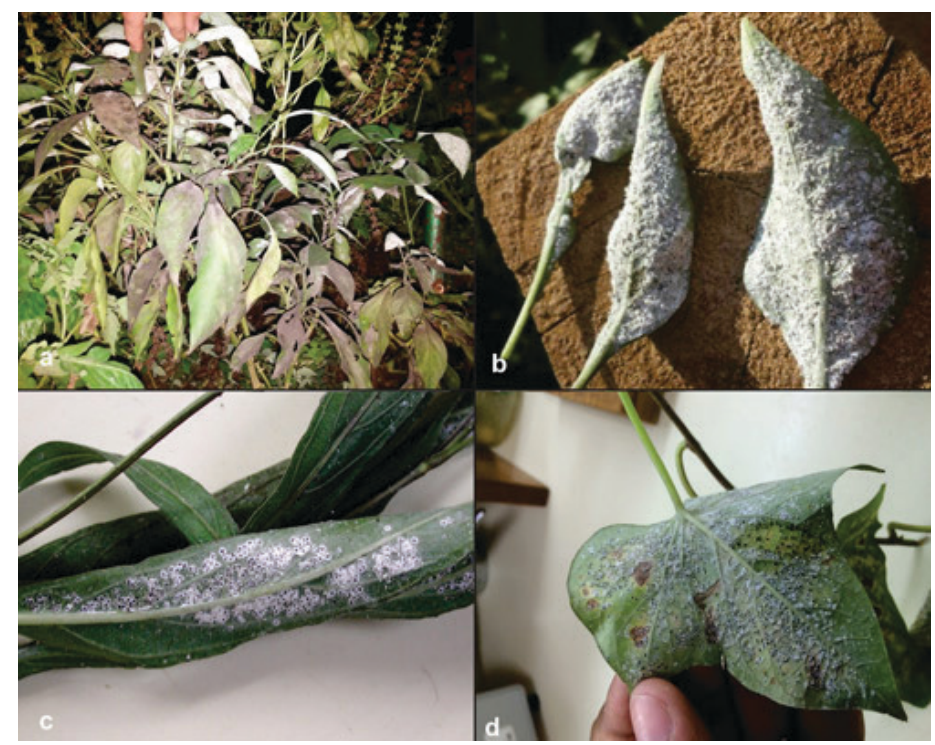

Figure 10. Plant infested with Aleurotrachelus trachoides Back. Infestation on Capsicum annuum L. (pepper) in Sarasota (a-b), Ruellia simplex Wright (Mexican petunia) in Stuart (c), Ipomoea batatas (L.) Lam. (sweet potato) in Miami (d).

Credits: Muhammad Z. Ahmed and Catharine Mannion, UF/IFAS

According to the Universal Chalcidoidea Database (Natural History Museum, UK), Encarsia brasiliensis Hempel, Encarsia cubensis Gahan, Encarsia formosa Gahan, Encarsia nigricephala Dozier, Encarsia pergandiella Howard, Encarsia tabacivora Viggiani, and Eretmocerus gracilis Rose parasitize this species, but their use as effective biocontrol agents of Aleurotrachelus trachoides is still a subject of investigation. In order to develop a long-term sustainable management program for this pest, researchers at the University of Florida, USDA-ARS, and FDACS are working on a collaborative project to evaluate potential commercial and naturally occurring whitefly biocontrol agents, such as Delphastus pallidus LeConte, Delphastus catalinae Horn, Encarsia sophia Girault \& Dodd and Encarsia noyesi Hayat against Aleurotrachelus trachoides. Another potential biocontrol agent may prove to be the predatory beetle, Axinoscymnus puttarudriahi Kapur \& Munshi, which has been found preying upon Aleurotrachelus trachoides infesting pepper plants in India (Ramanujam et al. 2014).

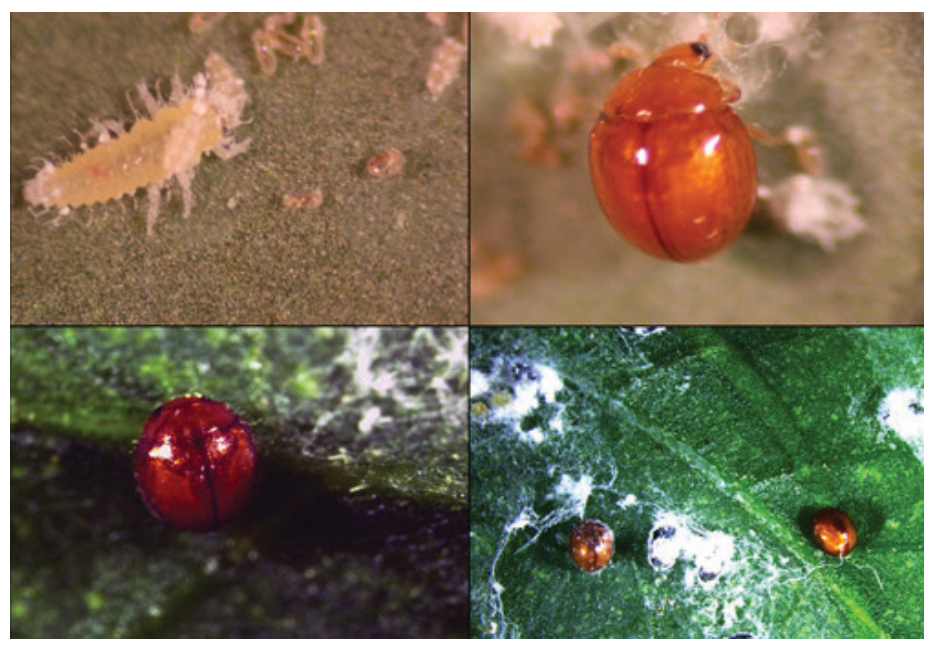

Figure 11. Delphastus pallidus (LeConte) immature and adult feeding on Aleurotrachelus trachoides Back, on Capsicum annuum L. (pepper). Credits: Lance S. Osborne, UF/IFAS

\section{Selected References}

EPPO. 2015. “Aleurotrachelus trachoides (Hemiptera: Aleyrodidae)". European and Mediterranean Plant Protection Organization. (18 July 2016).

EPPO Global Database. 2016. Aleurotrachelus trachoides hosts. (18 July 2016)

Evans GA. 2007. “The whiteflies (Hemiptera: Aleyrodidae) of the world and their host plants and natural enemies". USDA/Animal Plant Health Inspection Service (APHIS). (18 July 2016)

Natural History Museum. 2016. "Chalcidoid associates of named taxon.” Universal Chalcidoidea Database. (18 July 2016)

Ramanujam B, Shylesha AN, Joshi S, Murthy KS, Rangeshwaran R, Mohan M, Subhaharan K, Verghese A. 2014. "All India coordinated research project on biological control of crop pests annual progress report 2014-15”. ICAR National Bureau of Agricultural Insect Resources Bangalore, 560024. (18 July 2016) 